\title{
RITOS DE PASSAGEM DE ESTUDANTES DE CLASSES MULTISSERIADAS RURAIS NAS ESCOLAS DA CIDADE
}

\author{
RITES OF PASSAGE OF STUDENTS FROM MULTISERIATE \\ CLASSES IN CITY SCHOOLS
}

\section{RITOS DE PASAJE DE ESTUDIANTES EN GRUPOS MULTIGRADO RURALES A LAS ESCUELAS DE LA CIUDAD}

Elizeu Clementino de Souza*

Professor Titular do Programa de Pós-Graduação em Educação e Contemporaneidade, da Universidade do Estado da Bahia; Coordenador do GRAFHO (Grupo de Pesquisa (Auto)biografia, Formação e História Oral);

Pesquisador 1D CNPq.

Nanci Rodrigues Orrico ${ }^{* *}$

Professora substituta da Universidade Federal do Recôncavo da Bahia; Membro do GRAFHO (Grupo de Pesquisa (Auto)biografia, Formação e História Oral)

Fábio Josué Souza Santos ${ }^{* * *}$

Professor Assistente da Universidade Federal do Recôncavo da Bahia; Membro do GRAFHO (Grupo de Pesquisa (Auto)biografia, Formação e História Oral).

Ana Sueli Teixeira de Pinho***

Professora da Universidade Católica do Salvador; Vice coordenadora do Projeto:

"Multisseriação e trabalho docente: diferenças, cotidiano escolar e ritos de passagem", na Fundação de Amparo à Pesquisa do Estado da Bahia; Membro do

GRAFHO (Grupo de Pesquisa (Auto)biografia, Formação e História Oral).

\footnotetext{
"Doutora Sanduíche na Faculdade de Psicologia e Ciências da Educação/Universidade de Lisboa; Doutora em Educação pela Universidade Federal da Bahia; Mestre em Educação pela Universidade Federal da Bahia.

** Mestranda do Programa de Pós-Graduação em Educação e Contemporaneidade da Universidade do Estado da Bahia; , Especialista em Educação Inclusiva pela Faculdade de Santa Cruz da Bahia.

*** Doutor e Mestre em Educação e Contemporaneidade pela Universidade do Estado da Bahia.

**** Doutora em Educação e Contemporaneidade pelo Programa de Pós-graduação em Educação e Contemporaneidade da Universidade do Estado da Bahia.
} 
Resumo: O texto objetiva discutir ritos de passagem de estudantes concluintes do $5^{\circ}$ ano do Ensino Fundamental, em classes multisseriadas em escolas rurais para as escolas da cidade, onde são obrigados a se matricular a fim de dar continuidade aos seus estudos. A partir desta problemática, ou seja, a negação do acesso à educação pública de qualidade, expressa por meio da baixa frequência ou até mesmo inexistência de escolas dos Anos Finais do Ensino Fundamental nas localidades rurais onde esses estudantes residem, é possível inferir a adoção de uma lógica de abandono, precarização e negação da escolarização para todos, por parte dos sistemas públicos de ensino. Busca-se, assim, compreender a inserção desses estudantes nas escolas da cidade, no sentido de apreender o modo como vivenciam essa transição e se reconhecem como sujeitos desse processo educativo. Para entender a dinâmica referida, teoricamente o texto ancora-se nos conceitos de diferença, diversidade, ritos de passagem e multisseriação, além de investigar tensões relacionadas às configurações do espaço rural brasileiro contemporâneo, às políticas públicas para a Educação rural/do campo e à política nacional de transporte escolar. Do ponto de vista metodológico, adotamos princípios da pesquisa (auto)biográfica, com ênfase na realização de diferentes dispositivos de escritas, de entrevistas narrativas e também de análise documental, tendo em vista socializar algumas intervenções e práticas de acompanhamentos desenvolvidos em escolas que acolhem os estudantes das áreas rurais, como férteis para a construção de outras formas de inclusão dos egressos das classes multisseriadas nas escolas da cidade.

Palavras-chave: Educação rural. Multisseriação. Ritos de passagem. Inclusão escolar.

Abstract: The text aims to discuss rites of passage of students graduating the fifth grade of elementary school, in multigrade classes in rural schools that, to give continuity to studies, are required to enroll in city schools. From this issue, that is the denial of access to quality public education, given the observation of the low frequency or even absence of schools in the final years of elementary school in rural localities where these students live, it is possible to infer that this phenomenon seems to reveal the adoption of an abandonment logic, precariousness and denial of education for all, by public schools systems. Therefore, we seek to understand the inclusion of these students in city schools, in order to learn how they experience this transition and recognize themselves as a subject of this educational process. To understand the dynamic referred, theoretically the text has support on the concepts of difference, diversity, rites of passage, and multigrade. It also investigates tensions related to settings of contemporary Brazilian rural areas, to public policies for the rural/countryside Education and the national schools transport policy. From a methodological 
point of view, we adopted principles of (auto)biographical research, with emphasis on conducting different scripts devices, of narratives interviews and also documented analysis, in order to socialize some interventions and monitoring practices developed in schools that welcomes students in rural areas, as being fertile for building other forms of inclusion of the graduates of multigrade classes into city schools.

Keywords: Rural education. Multigrade. Rites of passage. School inclusion.

Resumen: El presente texto tiene por objetivo discutir los ritos de pasaje de estudiantes que han concluido el $5^{\circ}$ año de la Educación Primaria en grupos multigrado en escuelas rurales que, con el fin de continuar sus estudios, son obligados a matricularse en escuelas de la ciudad. A partir de esta problemática, o sea, la negación al acceso a la educación pública de calidad, expresada por medio de la baja frecuencia, o al mismo tiempo de la inexistencia de escuelas con los años finales de Educación Primaria en las localidades rurales donde esos estudiantes residen, es posible inferir, por parte de los sistemas públicos de educación, la adopción de una lógica de abandono, precarización y negación de la escolarización para todos. Por lo tanto, se busca comprender la inclusión de esos estudiantes en las escuelas de la ciudad, con el fin de aprehender el modo como vivencian esa transición y se reconocen como sujetos de ese proceso educativo. Para entender la dinámica referida, teóricamente el texto se fundamenta en los conceptos de diferencia, diversidad, ritos de pasaje y multigrado, además de investigar las tensiones relacionadas con las configuraciones del espacio rural brasileño contemporáneo, las políticas públicas para la Educación rural/de campo y la politica nacional de transporte escolar. Desde el punto de vista metodológico, adoptamos principios de investigación (auto)biográfica, con énfasis en la realización de diferentes dispositivos de escritura, de entrevistas narrativas y también de análisis documental, a fin de socializar algunas intervenciones y prácticas de acompañamiento desarrolladas en las escuelas que acogen a los estudiantes de las áreas rurales, en tanto materia fértil para la construcción de otras formas de inclusión de los egresados de los grupos multigrado en las escuelas de la ciudad.

Palabras clave: Educación rural. Multigrado. Ritos de pasaje. Inclusión escolar.

\section{POR SER DE LÁ: DIÁlogOS INICIAIS}

A intenção de discutir o ingresso de estudantes habitantes de áreas rurais em escolas da cidade exige, a priori, o entendimento de que historicamente as populações rurais brasileiras padecem com a falta de políticas públicas que atendam aos seus 
interesses. $\mathrm{Na}$ área educacional prevaleceu sempre o abandono, o que tem obrigado, desde muito tempo, os estudantes de territórios rurais a migrarem para a cidade, na busca de matrículas que lhes garantam o ingresso inicial na escola ou a continuidade de seus estudos.

Somente nas últimas décadas, por força da pressão dos movimentos sociais e de estímulos do Governo Federal, a implantação de algumas políticas no âmbito das redes municipais de ensino tem provocado algumas alterações neste quadro. ${ }^{1}$ Duas alternativas têm sido recorrentes desde então:

a) a construção dos chamados "Polos" ou "Núcleos Educacionais" em áreas rurais, aglutinando, assim, a matrícula de várias escolas isoladas, que, então, são desativadas, o que revela uma visão economicista impregnada no gerenciamento do sistema, visando diminuir custos;

b) e a oferta de transporte escolar que garanta o deslocamento diário dos estudantes destas áreas para as cidades, favorecendo, assim, a continuidade de seus estudos.

No Estado da Bahia, ainda que pese a escassez de estudos sobre essas políticas, pode-se afirmar que a "nucleação escolar" tem sido uma orientação bastante adotada pelos municípios de maior extensão territorial. Conquanto apresente maior comodidade para os estudantes das áreas rurais, dispensando-os de grandes deslocamentos, esta alternativa não se tem revestido em impactos significativos na vida desses estudantes e de seus familiares, pois o currículo dessas escolas permanece "urbanocêntrico", deslocado das necessidades imediatas e cotidianas das comunidades onde estão instaladas.

Em municípios de menor extensão territorial, a alternativa mais frequente tem sido a oferta de matrículas apenas para os Anos Iniciais do Ensino Fundamental ( $1^{\circ}$ ao $5^{\circ}$ Ano) nas escolas das áreas rurais, também chamadas de "escolas da roça". Além disso, tem-se também a oferta de transporte escolar para que os estudantes se desloquem, diariamente, do interior do município para as sedes das suas respectivas cidades, dando prosseguimento aos seus estudos nos Anos Finais do Ensino Fundamental e no Ensino Médio. Entretanto, essa prática, considerada excludente, à medida que desvincula o estudante do seu local de origem, não oportuniza situações que valorizem sua cultura e identidade de sujeito do campo. Essa constatação tem suscitado em nós, enquanto pesquisadores, inquietações e desejo de pesquisas e de novos aprofundamentos sobre a temática. 
As questões apresentadas neste texto tomam como referência resultados da pesquisa Multisseriação e trabalho docente: diferenças, cotidiano escolar e ritos de passagem, ${ }^{2}$ objetivando minimizar processos de exclusão sofridos por esses estudantes e elaborar materiais e propostas pedagógicas que acolham suas especificidades, sob a coordenação do Grupo de Pesquisa (Auto)biografia, Formação e História Oral, da Universidade do Estado da Bahia (Grafho/Uneb), em parceria com os seguintes grupos: Diversidade, Narrativas e Formação (Diverso/Uneb); Educação do Campo e Contemporaneidade (Uneb); Currículo, Avaliação e Formação (CAF/UFRB); Observale/Observatório da Educação do Campo no Recôncavo e Vale do Jiquiriçá/BA (UFRB); e o Laboratório Experice (Universidade de Paris 13/Paris 8).

As discussões de questões teórico-metodológicas vinculadas às classes multisseriadas e aos ritos de passagem campo/cidade têm nos permitido apreender dispositivos pedagógicos que são construídos cotidianamente pelos diferentes sujeitos das escolas, mediante ações colaborativas e intervenções pedagógicas entre professores das classes multisseriadas, das escolas dos Anos Finais do Ensino Fundamental e das universidades envolvidas.

A opção pelo estudo nas áreas rurais justifica-se pelo fato de:

[...] ali se concentrarem os piores indicadores educacionais, tanto no Brasil quanto no Estado da Bahia. Com isso, se admite que as áreas rurais, por força dos complexos processos de urbanização, foram historicamente banidas das pautas e agendas de discussão para definição de políticas que atendam às especificidades que são inerentes a essa população e, quando isso é feito a educação oferecida é de fato transplantada da lógica urbana para o meio rural. (SOUZA et al., 2012, p. 4).

Além disso, os estudantes das áreas rurais iniciam seus estudos, em sua grande maioria, em classes multisseriadas e essa forma de organização pedagógica ímpar, com uma dinâmica e ritmos próprios, tem sido muito pouco investigada. Sabemos que no contexto da Educação Rural/do Campo o maior número de matrículas situa-se em classes multisseriadas, caracterizadas pela oferta simultânea de várias "séries" em uma mesma turma, sob a regência de um único professor, por isso chamada também de "escolas unidocentes". Dados oficiais referentes ao ano de 2013 apontam a existência de 88.261 turmas multisseriadas no Brasil, sendo que o estado da Bahia, com 14.193, possui o maior percentual entre os estados brasileiros, 16,08\% (INSTITUTO NACIONAL DE ESTUDOS E PESQUISAS ANÍSIO TEIXEIRA, 2013). Apesar de sua forte presença no cenário brasileiro, especialmente nas regiões Nordeste e no estado da Bahia, esta tem sido uma realidade pouco investigada. Estado da arte 
realizado por Santos e Souza (2014) sobre as classes multisseriadas no Brasil a partir de dados do Banco de Teses e Dissertações da Capes, indicam a existência de apenas 7 teses e 55 dissertações, somando assim 62 trabalhos sobre o tema entre 1987 e 2012.

Segundo os autores, “o quantitativo de 62 trabalhos [...] é muito pequeno e, portanto, incapaz de permitir uma compreensão mais aprofundada do fenômeno da multissérie." (SANTOS; SOUZA, 2014, p. 30). Como afirmamos, a maioria destes alunos, ao concluir os Anos Iniciais do Ensino Fundamental, vive o que chamamos de ritos de passagem, saindo das classes multisseriadas das escolas rurais para escolas da cidade. Essa temática da mobilidade territorial/escolar e todas as implicações que os estudantes vivenciam neste processo também têm sido invisibilizadas nas produções acadêmicas.

Temos apreendido, a partir dos diálogos com os estudos de Souza e Santos (2014), Souza et al. (2011, 2008), Antunes-Rocha e Hage (2010), Damasceno e Beserra (2004) e Amiguinho (2003), que a indicação e a predominância histórica da lógica da prática educativa, pautada na transferência do modelo urbano adotado pela escola da cidade nas escolas rurais, vem reforçando para os sujeitos do meio rural a visão de que esse espaço tem, na maioria das vezes, sido configurado como inferior, atrasado e perto de extinção. Essa lógica, entretanto, já mostrou seu esgotamento, tornando inadiável o desenvolvimento de abordagens inovadoras que passem a considerar as especificidades dos territórios rurais e que busquem se adequar às experiências, necessidades e anseios das populações rurais, de modo que os sujeitos concretos, homens mulheres, crianças e jovens se reconheçam com as práticas educativas/escolares propostas e construídas para essas localidades (SOUZA et al., 2013), passando, nesta perspectiva, a conceber o campo como “[...] lugar de vida, onde as pessoas podem morar, trabalhar, estudar com dignidade de quem tem o seu lugar, a sua identidade cultural." (FERNANDES, 2004, p. 137).

Dessa forma, a intenção é problematizar questões relacionadas ao ingresso de estudantes oriundos das áreas rurais em escolas da cidade, apresentando algumas proposições metodológicas desenvolvidas em escolas de um dos municípios nos quais se desenvolve a pesquisa, Amargosa/BA, no sentido de apreender modos de expressão das diferenças e das diversidades por parte dos estudantes, habitantes de territórios rurais, e possíveis pistas para a inclusão destes, de forma efetiva, no âmbito educacional.

O texto está organizado em três seções: na primeira são articulados os conceitos de diferenças, multisseriação e ritos de passagem, em seguida explicita-se a relação entre pesquisa e inovação educacional, no sentido de apontar alternativas de escolarização que reconheçam os ritos de passagem vivenciados pelos estudantes habitantes das áreas rurais e, por fim, na última seção apontam-se algumas pistas para o 
enfrentamento da problemática pesquisada, numa perspectiva colaborativa entre pesquisadores, professores de classes multisseriadas, possibilitando-nos defender proposições didático-pedagógicas inclusivas, acolhedoras e que garantam a permanência dos estudantes de escolas rurais em seus locais de origem, respeitando-se as diferenças e superação de diferentes formas de desigualdades.

\section{DIFERENÇAS, MULTISSERIAÇÃO E RITOS DE PASSAGEM: DIÁLOGOS NECESSÁRIOS}

Trazer à tona o debate em torno dos desafios que marcam e segregam os estudantes de escolas rurais, por ocasião do ingresso nas escolas das cidades, implica a necessidade de aprofundamento em torno de temas estruturantes para essa discussão, dentre eles o da diferença. Emergindo na contemporaneidade, com acentuado destaque no cenário acadêmico e em diversos debates educacionais, essa temática coloca-nos frente à necessidade de superarmos visões etnocêntricas e eurocêntricas que ainda permeiam as práticas escolares em diversos contextos educacionais. Trata-se de ratificar o quanto se torna inviável, nos dias atuais, pensar uma escola cuja forma de concepção de mundo gire em torno da universalização de valores sociais, restringindo a amostragem do humano às culturas hegemônicas (TODOROV, 1993).

Sabemos que, ainda que recorrente na preocupação de estudiosos das ciências humanas, atualmente, esse tema parece ter seu interesse despertado:

[...] devido aos conflitos contemporâneos marcados por elementos que a realçam, a exemplo do aumento populacional, os fluxos migratórios em direção às grandes cidades, a má distribuição de renda, a miscigenação de etnias, os sincretismos religiosos, os movimentos sociais por direitos humanos e a disponibilização de alguns serviços, ainda que tardia e lenta, para segmentos historicamente marginalizados, possibilitando mais visibilidade nos espaços públicos das áreas urbanas. (SILVA, 2004, p. 29).

Essa visibilidade, conquistada por grupos socialmente marginalizados, faz emergir a necessidade de se pensar em práticas inclusivas para alunos egressos de escolas rurais, tornando essa uma discussão necessária na contemporaneidade. Além de se tornar inadiável, esse temática implica-nos na constatação de questões emergentes sobre este estudante que chega ao espaço escolar da cidade carregado de uma singularidade negada e visto a partir de uma ótica, temporalidade e representação negativas, pois como afirma Skliar, “[...] o tempo da modernidade e o tempo da escolarização insistem em ser, como decalques, temporalidades que só desejam a ordem, que teimam 
em classificar, em produzir mesmices homogêneas, íntegras, sem fissuras, a salvo de toda contaminação do outro." (SKLIAR, 2003, p. 45).

Vivemos, então, na escola, na contramão de toda emergência da questão da diferença e da diversidade cultural, sob uma lógica imperiosa de homogeneização, de desqualificação do outro em prol de um mesmo universal, de um modo de percepção único (SILVA, 2004). A chegada desse outro da escola rural é vista como desestabilizadora, já que esse estudante insiste em afirmar suas raízes identitárias, ainda que inconscientemente, no seu jeito singular de falar, de agir, de ser e de ver o mundo. Daí ratifica-se a necessidade de projetos e propostas que possam oferecer caminhos para se romper com lógicas, práticas e concepções instauradas nos espaços educacionais urbanos, mesmo quando estes recebem estudantes habitantes de áreas rurais. A intenção é provocar a emergência de outro olhar para estes sujeitos e outras práticas que reconheçam e aprendam a lidar com a diferença no cotidiano escolar.

Entendemos que essa nova visão não se concretizará, exclusivamente, por meio de leis ou decretos. Ainda assim, é relevante reconhecer que as legislações e as políticas públicas avançaram, no sentido de contemplar as especificidades das escolas rurais/do campo. Cabe destacar que, do ponto de vista das políticas públicas, em 2002, foi aprovada a Resolução CNE/CEB n. 01/2002, que institui as Diretrizes Operacionais para a Educação Básica do Campo; em 2010 foi publicado o Decreto n. 7.352, de 4 de novembro de 2010, que dispõe sobre a política de educação do campo e o Programa Nacional de Educação na Reforma Agrária - Pronera. Além disso, em 2011, a antiga Secretaria de Educação Continuada Alfabetização, Diversidade (SECAD) passa a ser nomeada de Secretaria de Educação Continuada Alfabetização, Diversidade e Inclusão (SECADI) e, por meio da sua Diretoria de Políticas de Educação do Campo, Indígena e para as Relações Étnico-Raciais, vem ratificando ações voltadas às escolas que se localizam nos territórios rurais, como o Procampo e o Programa Escola da Terra. Em março de 2012, ocorre a elaboração do Programa Nacional de Educação do Campo (Pronacampo), outro marco. Entretanto, essas conquistas, apesar de serem avanços valiosos, são ainda insuficientes e carecem de um olhar específico para o contexto das classes multisseriadas, que são aquelas turmas nas quais um único professor ensina a estudantes de faixa etária e séries diversas, fenômeno presente na maioria das escolas situadas nas áreas rurais, no Brasil.

Nossas inquietações, enquanto pesquisadores, têm nos levado a problematizar a necessidade de políticas públicas mais efetivas para as escolas de classes multisseriadas, já que estas são extremamente relevantes no contexto rural e da educação do campo, pois têm sido historicamente a única forma de acesso das populações rurais 
à escola. Apesar desta relevância social, elas não possuem o tratamento merecido pelo Estado e têm sido historicamente abandonadas, ignoradas, invisibilizadas pelas políticas públicas que, assentadas em ideais modernizadores e modernizantes, concebiam-nas como uma anomalia do sistema escolar e pressupunham a sua eliminação ${ }^{3}$ para que se pudesse promover uma educação de qualidade no campo.

Apesar do grande número de classes multisseriadas, principalmente na região Nordeste, ${ }^{4}$ a realidade desses espaços mostra um quadro extremamente precarizado (LEITE, 1999; SOUZA, 2012). Os espaços físicos recebem pouco investimento, os professores vivem sobrecarregados de trabalho, já que realizam, muitas vezes, atividades de docência, coordenação, faxina, preparação e distribuição de merenda, dentre outras. Além disso, a rotatividade docente nestes locais é imensa e, em grande parte, falta apoio das Secretarias de Educação; além de prevalecer um currículo inadequado e metodologias inapropriadas ao contexto da multisseriação (ANTUNES-ROCHA; HAGE, 2010; HAGE, 2005). Outro entrave no desenvolvimento dessas classes é que os saberes e modos de vida do camponês costumam ser desconsiderados nas propostas pedagógicas e nos materiais e livros didáticos adotados nesses locais, com base nas políticas públicas (ARROYO; CALDART; MOLINA, 2004).

$\mathrm{O}$ Estado, em vez de responder às necessidades das classes multisseriadas, desenvolvendo projetos que contribuam para melhorar suas condições de infraestrutura, de recursos didáticos, de condições de trabalho, de remuneração, formação docente, etc., trabalha na perspectiva da sua extinção. Nesse quadro, as iniciativas desenvolvidas sobre as classes multisseriadas têm sido a Nucleação Escolar e o Transporte Escolar de crianças das escolas da roça para as escolas da cidade. Este fenômeno de "migração por um turno", como denomina Santos (2006), tem sido ainda raramente estudado, apesar de sua forte presença no cenário educacional brasileiro nas últimas duas décadas, sobretudo após as reformas educacionais advindas da promulgação da nova Lei de Diretrizes e Bases da Educação Nacional (LDBEN), que gerou grandes implicações e mudanças nas políticas de financiamento e gestão das escolas.

A reflexão sobre a temática da passagem de estudantes de escolas rurais para as da cidade tem nos permitido construir algumas alternativas político-pedagógicas de intervenção entre pares e de acompanhamento, bem como de formação de professores, na perspectiva de que o trabalho docente possa considerar as diferenças dos sujeitos com disposições para os processos de aprendizagem e inclusão social.

Retifica-se, ainda, a necessidade de pesquisas sobre os ritos de passagem de estudantes do $5^{\circ}$ ano de classes multisseriadas de escolas rurais para escolas urbanas pela percepção de que, além da aculturação, há uma tensão marcada por três fases 
distintas: a chegada, nos primeiros meses; a adaptação, nos meses seguintes; e a conversão, a partir do segundo ou terceiro ano na escola (SANTOS, 2006). Esse processo merece ser estudado, já que é marcado por uma constante angústia nos estudantes entre serem e não serem provocados pelo duplo pertencimento geográfico/cultural a que estão submetidos: ser da roça ou da cidade. (SANTOS, 2006).

Nesta perspectiva, nosso entendimento é que o rito se constitui um processo dialético-social que (inter)media a relação caos e ordem. A escola (re)produz uma série de ritos: ritos de chegada, de ordem, de atividade, de passagem e ritos de identidade. Segundo Van Gennep (2008), os ritos de passagem marcam, do ponto de vista simbólico, uma transição social. Esta transição é um rito de formação com marcas evidentes da passagem - em sociedades tradicionais: uma escarificação, uma perfuração, uma tatuagem; e, nas sociedades marcadas pelo desenvolvimento econômico e por uma maior complexidade social e por maior obediência ao projeto da modernidade, as marcas são menos físicas, um diploma, um anel, uma cerimônia. Esses ritos de passagem iniciáticos, ao imprimirem sobre o sujeito uma marca simbólica, impõem também uma linguagem, ou seja, o sujeito informa por intermédio do signo sua agregação àquela identidade e a separação da identidade pretérita. As instituições educacionais configuram-se como importantes vetores de consolidação das marcas identitárias de uma sociedade, e sendo os ritos de passagem situação liminar na qual o sujeito se agrega a um novo horizonte, a escola tem papel fundamental na difusão e instituição dos ritos como marca formativa.

Para melhor entendimento desta questão, dialogamos com Van Gennep (2008), que concebe o rito como representação de uma transformação, a partir do qual o sujeito deixa de ser o que era para ser outra coisa em potência e apresenta ainda o risco da reflexão, pois neste momento o sujeito reflete sobre o seu papel em determinado grupo social, seus valores e questões morais, para seguir no processo de agregação de uma nova identidade. Para este autor, o rito se divide em três movimentos, a separação (que é o rito propriamente dito), a margem (o entre-rito e o imediatamente pós-rito, o liminar) e a agregação (a nova identidade pós-rito). Os ritos de passagem marcam, do ponto de vista simbólico, uma transição social, implicando novas disposições sobre a formação dos sujeitos ou modos de enfrentamento e negação por parte dos mesmos, evidenciados pelas marcas da passagem.

Pensar os ritos de passagem de estudantes de escolas multisseriadas do campo para escolas seriadas da cidade vai além de focar no processo de transição. Significa, para além disso, refletir sobre esses três movimentos relacionados por Van Gennep (2008), já que os estudantes das escolas rurais egressos de classes multisse- 
riadas, ao se deslocarem diariamente para a escola da cidade, para estudar os Anos Finais do Ensino Fundamental, vivem um rito de passagem caracterizado por um triplo deslocamento: mudança de ambiente geográfico (saem das áreas rurais para a cidade); mudança de nível de ensino (dos Anos Iniciais para os Anos Finais do Ensino Fundamental) e mudança na forma de organização da escolaridade (do ensino multisseriado, na escola rural, para um ensino seriado, na escola da cidade). Ainda, é possível considerar o deslocamento em torno das práticas culturais, modos de se relacionar com o tempo, entre outras mudanças que são vivenciadas ao longo desse percurso.

Esses ritos, que se caracterizam pelas suas singularidades e apesar de atingirem grandes contingentes de estudantes da roça, têm sido escassamente estudados, implicando outras possibilidades e diálogos a respeito das mobilidades vividas pelos sujeitos dos territórios rurais, bem como pelos silenciamentos, abandonos ou modos de resistências que são construídos por eles para permanecerem nas escolas urbanas, sem negarem suas identidades.

Postas essas questões iniciais sobre diferenças, ritos de passagem e multisseriação, buscaremos discutir modos próprios como temos desenvolvido ações de colaboração e de intervenção pedagógica entre pares, possibilitando novos olhares referentes a processos de mobilidade, rural-cidade, vividos pelos sujeitos das escolas rurais multisseriadas, a fim de que possam ter assegurado a continuidade de seus processos de escolarização.

\section{PESQUISA E INOVAÇÃO EDUCACIONAL: SOBRE RITOS DE PASSAGEM E ESCOLARIZAÇÃO}

As questões aqui sistematizadas tratam de aspectos teórico-metodológicos vinculados às escolas de classes multisseriadas, suas relações com o trabalho docente e o cotidiano escolar, buscando analisar ações de intervenção pedagógica, numa perspectiva colaborativa, que promovam a melhoria da qualidade da educação pública na Bahia, especialmente, no que diz respeito aos estudos sobre multisseriação e a criação de um ambiente mais acolhedor e inclusivo para os estudantes egressos das escolas rurais nas escolas urbanas.

A pesquisa-intervenção desenvolvida pelo grupo de pesquisa tem como parceiras quatro escolas públicas do Estado da Bahia, sendo duas municipais, multisseriadas e duas estaduais, que acolhem alunos egressos das escolas multisseriadas. Em Salvador situam-se a Escola Municipal de Botelho, localizada na Ilha de Maré e a Escola Estadual Marcílio Dias, situada no bairro de São Tomé de Paripe, no Subúrbio 
ferroviário de Salvador. Em Amargosa estão alocadas a Escola Municipal Helmano e Humberto de Castro, situada na localidade denominada Fazenda Timbó, zona rural do município e o Colégio Estadual Santa Bernadete, localizado na cidade. Tais escolas integram a pesquisa sobre multisseriação e trabalho docente, com ênfase em ações colaborativas sobre dispositivos pedagógicos, ritos de passagem e práticas de formação de professores, a fim de oportunizar e minimizar impactos relacionados ao processo de acompanhamento discente em escolas seriadas e urbanas.

As ações de pesquisa-formação têm se desenvolvido a partir de duas grandes entradas. A primeira analisa aspectos concernentes às condições de trabalho docente e do cotidiano escolar no contexto das escolas multisseriadas, à medida que tem oportunizado observar diferentes formas de interação que ocorrem no espaço da sala de aula, suas influências no processo de construção das temporalidades dos sujeitos e implicações nos processos de ensino e aprendizagem nas classes multisseriadas; além de possibilitar, numa perspectiva colaborativa, a elaboração de materiais didáticos que reconheçam as diferenças nestas realidades pedagógicas e valorizem a autoria das professoras, repercutindo na ressignificação das condições de trabalho docente. A segunda entrada tem como foco o acompanhamento e a observação dos modos como ritos de passagem são vividos por estudantes-egressos das escolas multisseriadas nas escolas da cidade, adotando diferentes formas de registro, por intermédio de práticas de mediação pedagógica e da observação da inserção dos egressos das classes multisseriadas nas escolas dos Anos Finais do Ensino Fundamental, analisando ritos de passagem, temporalidades e processos de aprendizagem.

Para atender os desafios propostos, a opção metodológica adotada na pesquisa-formação assenta-se em princípios da abordagem qualitativa, com base na pesquisa (auto)biográfica e na pesquisa narrativa, por considerar que a utilização dessas abordagens em educação busca evidenciar e aprofundar representações sobre as experiências educativas e escolares dos sujeitos, bem como potencializa entender diferentes mecanismos e processos históricos relativos à educação em seus diferentes tempos. Também porque as biografias educativas (SOUZA, 2006a, 2006b, 2015) permitem adentrar num campo subjetivo e concreto, mediante o texto narrativo, as representações dos diferentes sujeitos e atores sociais sobre as relações consigo próprios, com os outros e com o mundo, dando significados diversos. Tais opções tem nos permitido apreender e aprofundar aspectos diversos sobre as histórias de vida de professores e de estudantes das escolas parceiras, contribuindo para a superação de marginalizações e exclusões sociais. 
Temos utilizado como instrumentos de coleta de dados registros escritos, por parte das professoras e estudantes, também por meio da escrita de cartas, entrevistas narrativas, registro fotográfico e análise documental das escolas, tendo em vista contextualizar as escolas em seus territórios, abordando aspectos relacionados aos seus projetos pedagógicos que nos possibilitem, especialmente, discutir modos de organização das classes multisseriadas e acompanhar ritos de passagem campo/cidade dos sujeitos em mobilidade social e escolar. Tais ações também têm se desdobrado em dissertações e teses em andamento sobre as temáticas vinculadas à pesquisa, na vertente da abordagem (auto)biográfica, privilegiando a escuta sensível de professores e estudantes dos diferentes espaços pesquisados. Importante ressaltar que os dados empíricos colhidos até então têm se configurado como práticas de inovação educacional, à medida que têm oportunizado o mapeamento dos egressos, formas de registros e acompanhamento de possíveis superações de exclusões no cotidiano escolar.

Tomaremos, como eixo de análise para o presente texto, os dados relacionados às escolas de um dos municípios já citados, o de Amargosa, que se localiza no Recôncavo da Bahia e que conta atualmente com 41 classes multisseriadas nas 27 escolas rurais existentes. Segundo dados do Censo Populacional do Instituto Brasileiro de Geografia e Estatística (IBGE), no ano de 2010, o município registrou uma população total de 34.351 habitantes, sendo 24.891 (72,46\%) residentes na zona urbana e 9.460 (27,54\%) alocados na zona rural (BRASIL, 2011). O município tem uma economia baseada na agricultura familiar e na pecuária extensiva. Historicamente, teve sua economia baseada na cafeicultura - com escoamento da produção pela estrada de ferro que ligava o município à Nazaré. Na década de 1960, com a expansão do sistema rodoviário e o novo arranjo da rede urbana, o município ficou deslocado dos fluxos de escoamento de produção, em particular do eixo rodoviário representado pela BR-101 e BR-116, entrando em processo de estagnação econômica.

Atualmente, a região de Amargosa é constituída por um povo que sobrevive em grande parte da agricultura familiar, basicamente com o cultivo do cacau e outros tipos de produção agropecuária. Sendo assim, trazer à tona a discussão sobre educação nesse município é falar da necessidade de fortalecer a luta em prol de uma educação de qualidade para grande parte dos estudantes que iniciam sua trajetória escolar nas classes multisseriadas nas escolas localizadas nos territórios rurais.

No que diz respeito à oferta de vagas e saída dos estudantes das escolas rurais de Amargosa, a Prefeitura oferece matrículas apenas para a Educação Infantil e para os Anos Iniciais do Ensino Fundamental. Assim, os estudantes das áreas rurais são obrigados a migrarem para as escolas da cidade, diariamente, para darem conti- 
nuidade a seus estudos nos Anos Finais do Ensino Fundamental e no Ensino Médio. O deslocamento casa-escola-casa tem sido um percurso cansativo, desgastante e perigoso, obrigando muitos estudantes residentes em localidades mais distantes a acordarem em torno das 5 horas e retornarem às suas residências por volta das 14 horas. No percurso, feito em ônibus, eles passam por momentos tensos nas curvas, subidas e descidas das ladeiras, expõem-se, ainda, ao frio intenso, nos meses chuvosos de maio a agosto e à poeira irritante, nos períodos de primavera e verão. Ao chegarem às escolas da cidade, saindo de classes multisseriadas, sofrem com problemas já citados, como: preconceito, exclusão social, não se sentem acolhidos, nem encontram currículos e metodologias adequadas à sua realidade e identidade sociocultural. A reprovação e evasão escolar passam a ser frequentes entre esses/as estudantes. Além disso, os professores costumam desconhecer informações quanto à vinculação dos/as estudantes com os territórios que vivem, sobre a distância que percorrem e muitos possuem uma representação negativa sobre o contexto da multisseriação.

Buscando entender como os estudantes vivem este processo de transição - ritos de passagem e inclusão - entre a escola rural e a escola da cidade, no que se refere às expectativas que marcam esse momento, mapeamos o quantitativo de estudantes egressos da escola de classe multisseriada parceira no período de 2011 a 2015. O Quadro 1 explicita o quantitativo de alunos matriculados no $5^{\circ}$ ano, no período referido, perfazendo um total de 21 alunos egressos.

Quadro 1 - Quantidade de estudantes matriculados no $5^{\circ}$. ano na Escola Municipal Helmano e Humberto de Castro, por ano letivo - 2011-2015

\begin{tabular}{|l|c|c|c|}
\hline Ano letivo & Total & Masculino & Feminino \\
\hline 2011 & $\mathbf{5}$ & 3 & 2 \\
\hline 2012 & $\mathbf{2}$ & 1 & 1 \\
\hline 2013 & $\mathbf{5}$ & 2 & 3 \\
\hline 2014 & $\mathbf{3}$ & 1 & 2 \\
\hline 2015 & $\mathbf{6}$ & 4 & 2 \\
\hline Total & $\mathbf{2 1}$ & $\mathbf{1 1}$ & $\mathbf{1 0}$ \\
\hline
\end{tabular}

Fonte: adaptado de Secretaria Municipal de Educação de Amargosa, março 2015, pela equipe da pesquisa.

As ações relacionadas ao acompanhamento dos ritos de passagem vivenciados pelos estudantes entre as escolas parceiras possibilitou-nos mapear os egressos e construir dispositivos de intervenção pedagógica, iniciando com escritas de cartas sobre suas expectativas, por parte dos egressos, para que fossem entregues ao gestor e professores da escola estadual que acolheu e acolherá os estudantes egressos da escola 
multisseriada, bem como a realização de reunião com os pais e professores e, também, o processo de acompanhamento durante todo o período de matrícula, tendo em vista a preparação para o ano seguinte dos egressos e suas inclusões na escola da cidade.

Nas $\operatorname{cartas}^{5}$ dos estudantes das escolas da roça, percebemos suas expectativas, quando narram sobre suas emoções de se deslocarem dos seus territórios de origem na zona rural para a cidade, explicitando também sentimentos de ansiedade, medo do novo, mas também curiosidade em conhecer o diferente e outra forma de vida na ambiência escolar na cidade.

[...] quero dizer que sou filho de homem do campo e adoro morar no campo. Aqui é muito legal, adoro ir para o campo com meus pais, ver o ar puro, o canto dos pássaros, o verde da natureza $[\ldots]($ Carta 1$)$

Eu acho que na cidade vai ser diferente com vários professores e alunos e salas. Na minha escola atual só tem uma sala e poucos alunos. (Carta 2)

Eu acho que sair da minha escola para outra escola é muito bom. Imagino que a nova escola seja interessante. Gostaria que os professores fossem cuidadosos e gostassem de mim. (Carta 3)

Eu imagino que a escola "da rua" seja muito boa e que me respeitem como eu vou respeitar eles, os professores. Que os professores sejam muito calmos e que ensinem coisas boas e que eu conheça novos amigos. [...] Que eu possa passar de ano para entrar na faculdade e realizar meus sonhos. (Carta 4) (informações verbais).

Observa-se nas narrativas dos estudantes, questões relacionadas à disponibilidade de acolhimento por parte da escola, dos professores, de atenção por parte dos mesmos, de respeito às diferenças e da necessidade de se sentirem incluídos no novo espaço, já que se entende a inclusão como:

[...] um conjunto de práticas que subjetivam os indivíduos a olharem para si e para o outro, fundadas em uma divisão platônica das relações; também pode ser entendida como uma condição de vida em luta pelo direito de se autorrepresentar, participar de espaços públicos, ser contabilizado e atingido pelas políticas de Estado. (LOPES, 2011, p. 7).

A problemática do rito de passagem, ou seja, essa mobilidade dos sujeitos dos territórios rurais para as escolas da cidade exige atenção e definição de políticas públicas de acompanhamento, que possam minimizar transtornos e preconceitos construídos cotidianamente no espaço escolar. Do mesmo modo, remete para políticas de formação inicial e continuada que possam considerar as diferenças entre os diver- 
sos sujeitos que habitam o mundo da escola, respeitando-os e garantindo formas mais humanas e dignas de conviverem e aprenderem.

Outra ação significativa pensada para acompanhamento dos ritos de passagem perpassa pela tentativa de tornar a escola da cidade um ambiente mais acolhedor para esses estudantes que saem de pequenas escolas com uma ou duas turmas e vão para outra com 17 turmas, como é o caso do Colégio Santa Bernadete. Para isso, elegeu-se o que chamamos de "alunos/as acolhedores/as", que são estudantes da roça que já vivenciaram o rito de passagem e poderiam funcionar na escola como anfitriões destes recém-chegados, auxiliando-os no contato com professores, com os outros colegas, na movimentação na escola e da descoberta/vivência do cotidiano neste novo espaço. A continuidade das ações de acompanhamento, tendo em vista a inserção dos estudantes egressos de classes multisseriadas, ancorou-se na organização de uma Semana de Acolhimento para os estudantes das escolas rurais, com realização de atividades culturais, café da manhã e demais ações de acolhida envolvendo outros estudantes que já haviam vivenciado essa experiência, os professores e os demais colegas das turmas do $6^{\circ}$ ano da escola estadual parceira. Na oportunidade, os estudantes das escolas rurais chegaram à escola da cidade acompanhados por seus pais, e de membros da equipe da pesquisa, a fim de vivenciarem as diferentes atividades propostas.

Ainda assim, outras práticas foram empreendidas tanto por professores do Colégio Santa Bernadete quanto por uma das universidades envolvidas na pesquisa, com o objetivo de conhecerem melhor as escolas parceiras do projeto que têm classes multisseriadas; um exemplo consiste na realização de visitas às escolas rurais. Tais visitas às escolas rurais contaram com a participação de professores das diferentes instituições parceiras (Colégio Santa Bernadete, Universidade Federal do Recôncavo da Bahia, da Universidade do Estado da Bahia e ainda uma diretora da Secretaria de Educação do município de Amargosa que trabalha com as escolas multisseriadas). As visitas têm se configurado como momentos oportunos e formadores, pois, no deslocamento, vivenciamos transferências concernentes às experiências dos percursos e das realidades que esses estudantes vivem diariamente, possibilitando-nos compreensões acerca das condições de viagem, de infraestrutura, da distância percorrida para se chegar à escola da cidade e também oportunizaram o conhecimento da estrutura física e organização espacial e material da escola.

A realização de Seminários de pesquisa-ação-formação entre os participantes da pesquisa, tanto no espaço da universidade quanto das escolas, tem possibilitado a ampliação de conhecimentos dos professores das escolas estaduais, municipais multisseriadas, dos estudantes de iniciação científica, de mestrado e doutorado, por inter- 
médio da discussão e reflexão acerca das concepções epistemológicas que perpassam pelas temáticas da multisseriação, diferenças, ritos de passagem, cotidiano escolar, intervenções pedagógicas, etc. As trocas e oportunidades de aprendizagens têm sido intensas e desencadearam a necessidade de maiores estudos, além de encaminhamentos teórico-metodológicos sobre a elaboração conjunta de verbetes com os conceitos operados na pesquisa, de roteiros didáticos com as professoras de classes multisseriadas. Neste momento, debruçamo-nos na elaboração de cadernos temáticos, os quais tratarão das seguintes temáticas: 1) Multisseriação, seriação e trabalho docente; 2) Cotidiano escolar, diferenças e trabalho docente; 3) Ruralidades, ritos de passagem e acompanhamento escolar; 4) Ruralidades, práticas pedagógicas e inovação educacional. Tais cadernos tomarão como referência os dados coletados no processo da pesquisa e serão escritos coletivamente com a participação de toda a equipe, permitindo ampliações dos conceitos, implicando nas práticas pedagógicas e, sobremaneira, em dispositivos concernentes ao acompanhamento e outras formas de acolhimento e inclusão dos alunos de classes multisseriadas de territórios rurais em escolas da cidade.

Do ponto de vista da pesquisa colaborativa (FIORENTINI, 2004) entre pesquisadores e docentes das instituições parceiras, daremos continuidade ao estudo por meio da organização de grupos de discussão e da realização de entrevistas biográfico-narrativas com os sujeitos que integram a pesquisa, a fim de aprofundar suas experiências sobre os ritos de passagem, questões concernentes aos processos de aprendizagens na escola da cidade, formas de enfrentamento ou não de discriminação e preconceitos que poderão viver ou vivem no ambiente escolar. Ainda assim, buscaremos construir com os professores das diferentes escolas que integram a pesquisa a construção de roteiros didáticos para subsidiar o trabalho docente em classes multisseriadas, bem como a escrita dos cadernos temáticos. Tais ações voltam-se para disposições de formação continuada dos professores das escolas multisseriadas, uma vez que poderão subsidiá-las no trabalho docente nas escolas rurais, com vistas à construção de outras táticas vividas sobre os ritos de passagem de estudantes de escolas multisseriadas para o segundo segmento do ensino fundamental em escolas estaduais.

Nesta perspectiva, as ações de pesquisa-ação-formação colaborativa, na vertente dos estudos (auto)biográficos voltam-se para o fortalecimento de redes de pesquisa-formação entre universidade e escolas de Educação Básica, contribuindo para a melhoria da educação pública, das condições de trabalho docente nas classes multisseriadas e da inclusão dos estudantes que concluem sua escolaridade em escolas de áreas rurais para estudar nas escolas da cidade, fazendo com que esses possam prosseguir com seus estudos, sem perder sua singularidade e identidade cultural. 


\section{PARA CONTINUAR O Diálogo: Algumas PiSTAS CONCLUSIVAS}

Esse texto insere-se numa temática silenciada e invisibilizada nas políticas públicas - a dos ritos de passagem e inclusão de estudantes de escolas de áreas rurais nas escolas da cidade -, exigindo aprofundamento teórico-metodológico, tendo em vista que contempla um grande contingente de estudantes brasileiros.

Em notas conclusivas, evidenciamos neste artigo a necessidade de rompermos silêncios e fronteiras - geográficas, sociais e culturais - no sentido de valorizar as particularidades das escolas rurais e seu contexto ímpar de organização pedagógica, o das classes multisseriadas, assim como ratificamos a necessidade de adentrarmos na multiplicidade de temas e dilemas que se descortinam na passagem dos estudantes deste contexto escolar para o seriado das escolas da cidade.

Nesse sentido, um balanço dos nossos estudos e ações desenvolvidas até então no âmbito da pesquisa Multisseriação e trabalho docente: diferenças, cotidiano escolar e ritos de passagem coloca-nos diante da urgente necessidade de uma escuta sensível acerca das expectativas que os estudantes da roça, egressos de escolas multisseriadas, têm ao ingressarem na escola da cidade e de como vivem estes ritos e suas implicações com tais processos de transição. Além disso, confirma nosso compromisso de problematização em torno de temáticas e realidades invisibilizadas, como a da multisseriação, da inclusão de estudantes de escolas rurais nas escolas da cidade, da aculturação e dos ritos de passagem vivenciados nesse processo, a fim de promover a ampliação de outros olhares sobre os discursos e concepções instauradas nos diferentes contextos educacionais pesquisados.

Acredita-se que a persistência no desenvolvimento de novas pesquisas e na criação de ações e propostas didático-pedagógicas mais inclusivas e acolhedoras para os estudantes da roça nas escolas urbanas favorecerá a configuração de um "novo" rural, que fuja dos estereótipos do campo como local de atraso. Para isso, aposta-se na articulação universidade/escolas de Educação Básica e nos estudos que valorizem as interfaces entre rural/urbano, destacando, significativamente, modos diversos de respeito às diferenças e superação das desigualdades de raça, gênero, de condições sociais e de origem dos sujeitos.

Espera-se, por fim, que os novos caminhos e horizontes descortinados a partir das pesquisas e ações já iniciadas como ação de pesquisa-ação-formação colaborativa, possibilitem inovações educacionais que possam legitimar a nossa crença 
de que é possível fazer de cada espaço educacional um local onde caibam todos os mundos e sujeitos, respeitando-os.

Notas explicativas:

${ }^{1}$ Para a década de 1990, o principal estímulo foi a descentralização financeira promovida pela criação do Fundef, atualmente transformado em Fundeb (Cf., a esse respeito, VERHINE, 1999; DUARTE, 1999; OLIVEIRA et al., 1999), além de repasses, nos últimos anos, de verbas para aquisição de veículos para transporte escolar, feitos por órgãos, como o Fundo Nacional de Desenvolvimento da Educação (FNDE). No caso dos anos 2000, a pressão dos movimentos sociais do campo também tem contribuído para esta ampliação.

${ }^{2}$ A referida pesquisa é financiada pela Fundação de Amparo à Pesquisa do Estado da Bahia (Fapesb), no âmbito do Edital 028/2012 - Prática Pedagógicas Inovadoras em Escolas Públicas e do MCTI/CNPq, Chamada Universal n. 14/2014, tendo iniciado no ano de 2013 e encontra-se atualmente em fase de desenvolvimento, com conclusão prevista para o final de 2016.

${ }^{3}$ As propostas de eliminação do ensino multisseriado caminham sempre no sentido de se promover a seriação escolar. Para tanto, são implementadas propostas, como: 1) Garantia do funcionamento das escolas rurais, seguida da reorganização da distribuição das matrículas de modo que cada escola contenha apenas uma série, o que implica um reordenamento da logística de transporte escolar do município (SANTOS, 2006); 2) Fechamento das pequenas escolas rurais multisseriadas e deslocamento dos alunos para Escolas Polos ou Escola Núcleo, estabelecimentos de médio ou grande porte que, recebendo os alunos das escolas multisseriadas distribuem-nos em séries, separadamente; 3) Fechamento das escolas multisseriadas e deslocamento dos alunos para escolas da cidade.

${ }^{4}$ Em 2013 o Nordeste respondia por 56,10\% do quantitativo de 88.261 turmas multisseriadas existentes no Brasil em 2013. As demais regiões possuem os seguintes percentuais: Norte: $24,06 \%$, Sudeste: $11,72 \%$, Sul: 4,94\% e Centro Oeste: 3,16\% (BRASIL, 2013).

${ }^{5}$ Os excertos aqui utilizados correspondem às cartas escritas pelos estudantes, porém, para garantir a preservação da identidade dos mesmos, optamos por identificá-los com a palavra carta 1 a 4 .

\section{REFERÊNCIAS}

AMIGUINHO, A. Educação e mundo rural: percursos biográficos, intervenção e pesquisa. Educação, Sociedade \& Culturas, Porto, Portugal: CIIE/Edições Afrontamentos, n. 20, p. 9-42, 2003.

ANDRADE, M. Investigação sobre a transição dos alunos do ensino fundamental I para ensino fundamental II. 2011, 39 f. Trabalho de Conclusão de Curso (Graduação em Pedagogia)-Universidade Estadual de Londrina, Londrina, 2011.

ANTUNES-ROCHA, M. I.; HAGE, S. M. (Org.). Escola de direito: reinventando a escola multisseriada. Belo Horizonte: Autêntica, 2010. (Coleção Caminhos da Educação do Campo; v. 2).

ARRIOYO, M.; CALDART, R. S.; MOLINA, M. C. (Org.). Por uma educação do campo. Petrópolis: Vozes, 2004. 
DAMASCENO, M. N.; BESERRA, B. Estudos sobre educação rural no Brasil: estado da arte e perspectivas. Educação e Pesquisa, São Paulo, v. 30, n. 1, p. 73-89, jan./abr. 2004.

DUARTE, M. Limites à educação básica: expansão do atendimento e relação federativa. In: OLIVEIRA, D.; DUARTE, M. (Org.). Política e trabalho na escola. Belo Horizonte: Autêntica, 1999. p. 237-252.

FERNANDES, B. M. Diretrizes de uma caminhada. In: ARROYO, M. G. et al. (Org). Por uma educação do campo. Petrópolis: Vozes, 2004. p. 133-145.

FIORENTINI, D. Pesquisar práticas colaborativas ou pesquisar colaborativamente? In: BORBA, M.; ARAÚJO, J. L. Pesquisa Qualitativa em Educação Matemática. Belo Horizonte: Autêntica, 2004. p. 47-76.

HAGE, S. M. Educação do campo na Amazônia: retratos de realidade das escolas multisseriadas no Pará. Belém: Gráfica e Editora Gutemberg Ltda, 2005.

IBGE. Censo Demográfico 2010. Características da população e dos domicílios: resultados do universo. Rio de Janeiro: IBGE, 2011. Disponível em: <http://www. ibge.gov.br/home/estatistica/\%20\%20populacao/censo2010/caracteristicas_da_populacao/\%20\%20resultados_do_universo.pdf>. Acesso em: 10 mar. 2013.

INEP. INSTITUTO NACIONAL DE ESTUDOS E PESQUISAS ANISIO TEIXEIRA. Sinopse Estatística da Educação Básica. Brasília, DF: INEP, 2013.

LAGE, A. C. M.; BOEHLER, M. Multissérie em questão: Classes multisseriadas formam um contigente enorme em escolas do campo de todo o Brasil, mas continuam marginalizadas. Letra A, Belo Horizonte: Faculdade de Educação/UFMG, ano 9, n. 36, p. 8-11, out./nov. 2013.

LEITE, S. C. Escola rural: urbanização e políticas educacionais. São Paulo: Cortez, 1999.

LOPES, M. C. Prefácio: Políticas de inclusão e governamentalidade. In: THOMA, A. da S.; HILLESHEIM, B. (Org.). Políticas de inclusão: gerenciando riscos e governando as diferenças. Santa Cruz do Sul: Edunisc, 2011, p. 7.

OLIVEIRA, D.; DUARTE, A. (Org.). Política e trabalho na escola. Belo Horizonte: Autêntica, 1999.

SANTOS, F. J. S. dos. Nem "tabaréu/ao", nem "doutor/a", o/a aluno/a da roça na escola da cidade: um estudo sobre escola, cultura e identidade. Dissertação (Mestrado em Educação e Contemporaneidade)-Universidade do Estado da Bahia, Salvador, 2006. 
SANTOS, F. J. S.; SOUZA, E. C. de. A produção acadêmica sobre o tema "classes multisseriadas" no Brasil: um olhar sobre as teses e dissertações (1987-2012). In: XXII ENCONTRO DE PESQUISA EDUCACIONAL DO NORTE E NORDESTE, 22., 2014, Natal. Anais... Natal, 2014.

SILVA, L. M. da. A negação da diferença: um estudo sobre as interações de alunos com deficiência visual na escola pública. Doutorado em Educação: História, Política e Sociedade. 2004. Disponível em: <http://www.cdi.uneb.br/pdfs/teses/2004/luciene_maria_da_silva.pdf $>$. Acesso em: 10 mar. 2013.

SKLIAR, C. A educação e a pergunta pelos Outros: diferença, alteridade, diversidade e os outros "outros". 2003. Disponível em: <file://C:/Users/FRAN\%C3\%87A/ Documents/ Downloads/1244-15464-1-PB.PDF>. Acesso em: 28 set. 2013.

SOUZA, E. C. A arte de contar e trocar experiências: reflexões teórico-metodológicas sobre história de vida em formação. Revista Educação em Questão, v. 25, n. 11, jan./abr. 2006, p. 22-39, Natal: Edufrn, 2006a. Disponível em: <http://www. revistaeduquestao. educ.ufrn.br/pdfs/v25n11.pdf>. Acesso em: 28 ago. 2013.

SOUZA, E. C. (Org.). (Auto)biografia e documentação narrativa: redes de pesquisa e formação. Salvador: Edufba, 2015.

SOUZA, E. C. (Org.). Educação e ruralidades: memórias e narrativas (auto)biográficas. Salvador: Edufba, 2012.

SOUZA, E. C. (Coord.). Multisseriação e trabalho docente: diferenças, cotidiano escolar e ritos de passagem. Salvador: Uneb; Fapesb, 2013. (Projeto apresentado à Fapesb no âmbito do Edital 028/2012).

SOUZA, E. C. O conhecimento de si: estágio e narrativas de formação de professores. Rio de Janeiro: DP\&A, Salvador: UNEB, 2006b.

SOUZA, E. C.; SANTOS, F. J. S. Educação rural e multisseriação: rompendo silêncios e indicando horizontes. In: SILVA, M. A.; CUNHA, C. (Org.). Educação Básica: políticas, avanços e pendências. Campinas: Autores Associados, 2014. p. 315-345.

SOUZA, E. C. et al. Sujeitos e práticas pedagógicas nas escolas rurais da Bahia: ações educativas e territórios de formação. Currículo sem Fronteiras, v. 11, n. 1, p. 156-169, jan./jun. 2011. 
SOUZA, E. C. et al. Cultura, multisseriação e diversidade: entre narrativas de vida e experiências docentes cotidianas. In: FERRAÇO, C. et al. (Ed.). Aprendizagens cotidianas com pesquisa: novas reflexões em pesquisa nos/dos/com os cotidianos das escolas. Rio de Janeiro: DP et al., 2008. p. 77-93.

TODOROV, Tzvetan. Nós e os outros: a reflexão francesa sobre a diversidade humana. Rio de Janeiro: Jorge Zahar, 1993.

VAN GENNEP, A. Los ritos de paso. Madrid: Alianza Editorial, 2008.

VERHINE, R. O FUNDEF: suas implicações para a descentralização do ensino e o financiamento da educação no Brasil. Revista da FAEEBA, Salvador, UNEB, n. 12, p. 131-151, jul./dez. 1999.

Artigo Recebido em: 15 de outubro de 2015 Aceito em: 13 de fevereiro de 2016

Endereço para correspondência: Rua Visconde de Cachoeira, 61, apt 102 A, Rio Vermelho, 41.950-710, Salvador, Bahia, Brasil; esclementino@uol.com.br 